\title{
Research on Organization of Mathematics Knowledge in Good Mathematical Cognitive Structure
}

\author{
Zezhong Yang ${ }^{1 *}$, Ming Zhu ${ }^{1}$, Zhaohua Qu ${ }^{1}$, Yanqing Zhang ${ }^{1}$ \\ ${ }^{1}$ Shandong Normal University, CHINA
}

Received 16 May 2017 • Revised 22 September 2017 • Accepted 6 October 2017

\begin{abstract}
This research adopted the method of network data analysis, chose 31 senior high school first-grade outstanding students as participants and 44 concepts about trigonometric function as materials, analyzed the organization of mathematics knowledge in good mathematical cognitive structure (GMCS) with the help of software Ucinet. The results indicated: (1) The connections between the concepts in GMCS were more extensive, especially those connections with higher tightness degree. (2) Most connections in GMCS were direct. (3) There were more abstract concepts as accumulation points connecting with others. (4) There were a number of concrete and frequently used concepts connecting with others directly. Therefore, the mathematics teachers should help students to construct extensive and direct connections between mathematics knowledge in their mind. These new findings expanded and deepened the current research about mathematical cognitive structure(MCS), pointed out the direction and target for educators helping their students form GMCS. Meanwhile, this research demonstrated the network data analysis method was feasible and valuable to analyze mathematics psychological issues.
\end{abstract}

Keywords: cognitive structure, mathematics knowledge, organization, connection

\section{INTRODUCTION}

Mathematical cognitive structure (MCS) was a specific concept presented by mathematical education researchers in the late 19th century based on the concept of cognitive structure in psychology (Cao and Cai, 1989; Wu and Guo, 1997; Tu, 2003; Yu, 2011; Alison et al., 2013). It was an internal hypothetical structure and used to represent the storage and the organization of mathematics knowledge (Bruner, 1989; Cao and Cai, 1989; Li, 2001; Tsai, 2001; He, 2002; $\mathrm{Yu}, 2004)$. Much mathematical education research had demonstrated the MCS formed in the process of mathematics learning and played a vital role in individual mathematical activities (Ausubel, 1963; Ausubel, 1994; Zhang, 2003; Yu, 2004; Sofia et al., 2017). It could affect individual not only to understand and master mathematics knowledge but also to apply mathematics knowledge, etc. (Skemp, 1971; Yang, 1993; Dixon, 2005; Zhang, 2007; Zhang, 2012). Therefore, in the process of mathematical teaching, almost all teachers expected to help the students to form a good mathematical cognitive structure (GMCS) (Wilkerson-Jerde \& Wilensky, 2011). To achieve this goal, numerous related research was conducted in recent years and obtained fruitful results.

Regarding the content of GMCS, Guan Peng and He Xiaoya thought GMCS should contain massive and varied basic mathematics knowledge, especially the knowledge about the production and the problem-solving strategy (Guan, 1998; He, 2002). The so-called production was a string of knowledge made up of the conditions and the related action. It was a program that some kinds of behaviors happen when certain conditions were given $(\mathrm{He}$, 2002; Kong and Zeng, 2009). The problem-solving strategy referred to the general guideline and idea which an individual could use to understand conditions, select methods and determine the steps in the process of problemsolving (Li, 1998). Wang Wenjing and Zheng Yanping thought GMCS should include the representation system of relations and the representation system of ideas. The relations representation was awareness of relations of mathematical knowledge, and the idea representation referred to the understanding of the cause of the relations

(C) Authors. Terms and conditions of Creative Commons Attribution 4.0 International (CC BY 4.0) apply. 


\section{Contribution of this paper to the literature}

- With the help of network data analysis method, this research analyzed the organization characteristics of mathematics knowledge in GMCS quantitatively.

- The results indicated the connections of mathematics knowledge in GMCS were more extensive and most of them was direct. There were more abstract knowledge connecting with others and a number of concrete and frequently used concepts connecting with others directly in GMCS.

- Mathematics teachers should help students to construct extensive and direct connections between mathematics knowledge in their mind, attach importance to the frequently and widely used mathematics knowledge and help students to construct the direct connections between this kind of mathematics knowledge and others.

between knowledge (Wang and Zheng, 2008). Mi Meng and Hou Wansheng proposed that GMCS should include much meta-cognitive knowledge (Mi and Hou, 2011).

As for the characteristics of knowledge in GMCS, Jin Qifeng, Wang Guangming, Han Bing and Wang Yue thought it should be reasonable, clear, individualistic, interconnected and flexible (Jin, 2002; Wang and Wang, 2004; Han and Wang, 2005). Wang Wenjing, Zheng Yanping, Jin Xiaofeng, Yan Zhengxiang, Huang Decheng, Han Bing and Wang Yanwen held the idea it should be stable and firm (Wang and Zheng, 2008; Jin, 2011; Yan and Huang, 2005; Han and Wang, 2005). Mi Meng, Hou Wansheng, Yan Zhengxiang and Huang Decheng thought it should be given a high-level "internalization" and deep understanding (Mi and Hou, 2011; Yan and Huang, 2005). Wang Guangming and Wang Yue thought the correlation density of knowledge in GMCS was larger; Different representation forms of the same mathematical knowledge were interlinked (Wang and Wang, 2004). Chen Jie thought it had the following three characteristics: (1) It could absorb new knowledge quickly; (2) It could provide the knowledge timely; (3) It could create new knowledge (Chen, 2003).

When it came to the organization of knowledge in GMCS, many scholars considered that the contents were organized in the form of network (Papert, 1993; Guan, 1998; Li, 2001; He, 2002; Wilkerson-Jerde \& Wilensky, 2011). Besides, Yan Zhengxiang and Huang Decheng thought that GMCS was ordered and well organized (Yan and Huang, 2005). Zhao Chunxiang and Jin Xiaofeng believed that the knowledge in GMCS could be divided into two parts, the first part and the second part. The knowledge belonging to the first part was general, and those belonging to the second part was the concrete (Zhao, 2013; Jin, 2011). Mi Meng and Hou Wansheng believed that the knowledge which had the highest degree of the inclusive level were in central position (Mi and Hou, 2011). Wang Wenjing and ZhengYanping thought that the organization of GMCS was a pattern of "standard pyramid" formed according to the level of the abstraction of mathematical knowledge. The most abstract and general knowledge was at the top of the "standard pyramid" while the subordinate knowledge was at the bottom (Wang and Zheng, 2008). $\mathrm{Yu}$ Ping proposed that mathematics knowledge in GMCS should be organized together based on the knowledge field and knowledge system. The so-called knowledge field was a knowledge network, in which the knowledge connected with each other according to their equivalence relations; the so-called knowledge system was a series of knowledge which was formed according to their relations about abstraction or deduction (Yu et al., 2011).

Reviewing these research, it could be seen many aspects of GMCS had been discussed and obtained fruitful results. However, there were still some aspects of GMCS need to be explored in depth, such as its density, subgroups, and centrality. Therefore, instead of using the qualitative method which was mostly adopted by the previous research, the further research which is conducted with the quantitative method which can make the research about GMCS to be more clear and precise is necessary and valuable (Lu and Yu, 2010; Sun and Yang, 2015). This research explores the organization of mathematics knowledge in GMCS with the quantitative method, focuses on the research question "what is organizational characteristics of the mathematics knowledge in GMCS?"

\section{THEORETICAL CONSIDERATIONS}

The MCS was an internal structure about mathematics knowledge (Bruner, 1989; Cao and Cai, 1989; Li, 2001; Tsai, 2001; He, 2002; Tu, 2003; Yu, 2004). It could be described as a network consisted of many nodes and their connections. The nodes were the mathematics concepts, signs, figure, formula, axiom, theorem and their properties (Papert, 1993; Wilkerson-Jerde \& Wilensky, 2011). Their connections were the relations between nodes (Guan, 1998; $\mathrm{He}, 2002)$. The MCS could be divided into three basic forms: linear structure, tree structure and network structure. These three basic structures could combine each other and construct a Three-dimensional and synthetical structure (Li, 2001). In which the quantity of nodes and the connections and the tightness of connections and the way of connections varied from person to person. The quantity of nodes and connections contained in mathematics gifted students' MCS was larger (Wang and Wang, 2004). In which the distribution of nodes was also uneven, that was the MCS could be divided into many respectively centralized substructures which formed around one or several 
important mathematics concepts or theorems (Yu, 2004). As for the organization of these nodes, some researchers referenced the perspectives of cognition psychologist about the cognitive structure and believed they could be classified many different layers (Wo, 2000; Wang and Zheng, 2008). The abstract mathematics knowledge was on the top, and the concrete mathematics knowledge was on the bottom. However, the other researchers did not believe it (Zhang and Chen, 2000).

As for the method to probe the MCS, the concept map method was considered as the most convenient and effective commonly at present (Novak, 1998; Liu, 1994; Ruiz-Primo \& Shavelson, 1997), because it could show clearly not only the quantity of knowledge and their connections, but also the integral organization of all knowledge (Preece, 1976; Zhang and Chen, 2000; Tsai, 2001; Ifenthaler et al., 2001). However, it was obviously inconvenient to conduct quantitative analysis (Zhang and Chen, 2000; Ifenthaler et al., 2001). So the researchers developed some new methods, such as flow-map method (Anderson and Demetrius, 1993), the technique of "establishment by the subject" (Liu, 1994; Enger, 1996; Ruiz-Primo \& Shavelson, 1997; Ruiz-Primo et al., 2001; Lavigne, 2005; Shavelson et al., 2005; Muller et al., 2008; Lindstrom \& Sharma, 2011), the method of "Pathfinder Associative Networks" (Casas et al., 2011; Geeslin \& Shavelson, 1975; Jonssen et al., 1993; Fenker, 1975; Preece, 1976; Wainer \& Kaye, 1974), and the method with HIMATT (Ifenthaler, 2011). After verifying by practice, it could be found these new methods were feasible, they promoted the quantitative research to cognitive structure and made the understanding of MCS to be more distinct and profound.

Recently, a new method, that was network data analysis method, was introduced in research of psychology to help the related quantitative analysis (Xu et al., 2011). This method used to analyze social network characteristics based on the calculation of data relation, such as density, centrality, and subgroups (Liu, 2009; Luo, 2010). The reason why it was introduced into research about psychology was that lots of psychological relation networks were similar with the social relation networks. Indeed, excepting the actual meaning of content involved in the psychological networks and social networks, the abstract connections which need to be discussed in two different networks were same (Ma et al., 2011). Additionally, it had been verified to be feasible and effective to research psychological problems (Hou et al., 2014). Therefore, when discussing the organization of mathematical knowledge of MCS, this method should be feasible and valuable, and it will bring us more new discoveries.

\section{METHOD}

\section{Participants}

We chose 31 first-grade senior high school outstanding students in mathematics learning respectively coming from two key senior high schools in Jinan city and two key senior high schools in Zibo city of Shandong province in China as participants. The reason why we chose them as participants were the primary students did not learn any knowledge about trigonometric function. When they were in junior high school, they were just arranged to learn some elementary concepts of trigonometric function, such as sine and cosine (Ministry of Education of the people's Republic of China, 2012). Only the senior high school students learn the 44 concepts of trigonometric function (Ministry of Education of the people's Republic of China, 2003). The reason why we chose outstanding students was their MCS were usually thought as the good (Tsai, 2001, Wang and Wang, 2004).

The reason why we chose students from the above four schools was the key senior high school in Jinan city and Zibo city had admittedly a higher level of mathematical education in China. The outstanding students in mathematics learning chosen from the above four schools had great representation. These students included 19 female students and 12 male students. Their average age was $16.12(M D=0.11)$.

The standards we adopted for selecting students were the most popular one in mathematical education currently, which focused on the students' performances in mathematical learning and their daily achievements. The outstanding students' mathematical learning was usually positive, stability, effective and efficient, their daily achievements were usually high (Maker, 1981; National Council of Teachers of Mathematics, 2000; Johnson, 2000).

The process that the outstanding students were selected was as follows: (1) selected a class randomly in each school mentioned above firstly. (2) selected the top 15 of students of that class according to the scores of the end examination of last semester secondly ( 15 was approximately the one-third of the number of all students in a class in Chinese senior high school. Thus, 60 students were selected totally). (3) analyzed these students' rankings among all students in their school, deleted the students whose ranking was not in top $10 \%$ of all students in their school. (13 students were deleted.) (4) analyzed the rest students' rankings at each chapter examination to identify their stability of learning. When the students started the chapter of trigonometric function, they had learned 7 chapters of the textbook and had 7 chapter examinations totally. After that, we deleted the students who were not always on top 15. (12 students were deleted). (5) analyzed the each student's daily performance of the rest students, deleted the students without enthusiasm for mathematics learning. (4 students were deleted.) 


\section{Materials}

We chose all 44 mathematics concepts related to trigonometric function from the most popular senior high school mathematics textbook in China published by people's education press as research materials. They are Periodic transformation, Acute angle, Trigonometric function value, Trigonometric function line, Tangent line, Cosine line, Sine line, Directed line segment, Tangent function, Cosine function, Sine function, Central angle, Radian, Angle system, Trigonometric function, Round angle, Quadrant angle, Terminal side, Initial line, Zero angle, Radian system, Arbitrary angle, Sinusoid, Phase, Initial phase, Cosine, Frequency, Amplitude, Definition domain, Function domain, Interval, Decreasing function, Increasing function, Even function, Odd function, Minimal positive period, Period, Periodic function, Functional image, Induced formula, Tangent function value, Cosine function value, Obtuse angle, Unit circle. The reason why we chose these concepts was their relations between each other were abundant, which could help us to find the organizational characteristics of MCS not only easily but also clearly. The reason why we chose a particular group of mathematics concepts as the material was that it can make the research more careful and in depth (Sofia et al., 2017).

\section{Data Collection}

This research was carried out after the students had finished the chapter of trigonometric function and learned all 44 concepts above. The process of data collection was as follows: (1) encouraged the students to recall all concepts about trigonometric function at first; (2) presented above 44 mathematical concepts to students to help them have a clear understanding of these concepts; (3) let each student draw a map of relations between these concepts according to his or her own understanding; (4) asked students to indicate the connection tightness degrees of each relation respectively with integer numbers 1 to 5 from the weakest to the strongest.

The reason why we encouraged students to recall at first and then provided students with all 44 concepts in this period was the focus of this research was the organization of knowledge in GMCS, we expected to know all relations of these concepts, so that we could find out their organizational characteristics in students' MCS instead of their storage characteristics.

In order to collect the data expediently and effectively, with the agreement of all students' parents and the help of their mathematics teachers, we took the way of cluster sampling then. There were totally 213 first-grade students in four classes, including 96 male students and 117 female students, 31 outstanding students, 127 medium students, and 55 general students. The general students were usually ranked behind 15 in chapter examinations, its selection process was similar with that of the outstanding students. Excepting the outstanding students and general students, the rest was regarded as medium students.

We received 213 concept relation maps at last. After rejecting 7 unclear and disorder sets (they all were general students' maps), finally we got 206 concept relation maps that were suitable for further analysis. The reason why the maps of medium and general students were also reserved was that we planned to compare their maps with the outstanding students' maps to find more characteristics of GMCS.

What needs to be declared is this research was carried out in accordance with the recommendations of "The guidelines of the International Committee of Medical Journal Editors and the Adolescent Mental Health Specialized Committee of Chinese Mental Health Association" with written informed consent from all parents of participants. All parents of participants gave written informed consent in accordance with the Declaration of Helsinki. Meanwhile, the ethics and academics committee of the School of Psychology at Shandong Normal University approved this research.

\section{Data Analysis}

To identify the characteristics of GMCS, we extracted the number representing the connection tightness degrees of concepts from the 206 concept relation maps mentioned above at first, transformed them into one-mode multivalued relations matrices, and calculated the average value matrices of three different level students respectively. Thereout, we analyzed the overall density, subgroups, ego density and ego centrality of their MCS with the help of network analysis software Ucinet6.0. We believe these four aspects were necessary and valuable to access to characteristics of GMCS.

\section{RESULTS}

\section{The Overall Density of MCS}

The overall density of a network was the ratio of numbers of actual relations to numbers of theoretical relations between members in the network. Its calculation formula was $n /(m \cdot(m-1) / 2)(n$ was the number of actual 
Table 1. The overall density values of MCS

\begin{tabular}{cccc}
\hline Critical value & Outstanding students & Medium students & General students \\
\hline 0 & 0.4725 & 0.4281 & 0.2579 \\
\hline 0.4475 & 0.2474 & 0.1195 & 0.0708 \\
\hline 0.875 & 0.1342 & 0.0391 & 0.0063 \\
\hline 1.3225 & 0.0751 & 0.0021 & 0.0011 \\
\hline 1.77 & 0.0402 & 0 & 0 \\
\hline
\end{tabular}

Table 2. The numbers of cohesive subgroups of MCS

\begin{tabular}{ccccc}
\hline \multirow{2}{*}{$\begin{array}{c}\text { Critical } \\
\text { value }\end{array}$} & Subgroups & $\begin{array}{c}\text { Outstanding } \\
\text { students }\end{array}$ & $\begin{array}{c}\text { Medium } \\
\text { students }\end{array}$ & $\begin{array}{c}\text { General } \\
\text { students }\end{array}$ \\
\hline \multirow{3}{*}{1} & Numbers of subgroups & 2 & 27 & 39 \\
\cline { 2 - 5 } & Numbers of subgroups which concepts are more than 3 & 2 & 3 & 0 \\
\cline { 2 - 5 } & Numbers of concepts in the biggest subgroup & 32 & 6 & 0 \\
\hline \multirow{2}{*}{2} & Numbers of subgroups & 28 & 44 & 44 \\
\cline { 2 - 5 } & Numbers of subgroups which concepts are more than 3 & 3 & 0 & 0 \\
\cline { 2 - 5 } & Numbers of concepts in the biggest subgroup & 12 & 0 & 0 \\
\hline \multirow{2}{*}{3} & Numbers of subgroups & 41 & 44 & 0 \\
\cline { 2 - 5 } & Numbers of subgroups which concepts are more than 3 & 1 & 0 & 0 \\
\cline { 2 - 5 } & Numbers of concepts in the biggest subgroup & 4 & 0 & 0 \\
\hline
\end{tabular}

relations, $m$ was the number of theoretical relations). So it could help researchers to find out the relative quantity of relations in a network (Liu, 2009; Luo, 2010).

To find out the differences precisely of the overall density of the networks of MCS of different level students, we picked up the maximum values respectively from three average matrices and calculated their average value firstly, that was 1.77 . With $0,1.77$ and the quartile of 1.77 , namely $0.4475,0.875$ and 1.3225 as equidistant critical values, we input the three average value matrices into Unciet6.0 and calculated overall density values in above 5 cases of three average value matrices by executing the command "Network $\rightarrow$ Cohesion $\rightarrow$ Density overall".

When the critical value was 0 , all relations would be considered. When the critical value was 0.4475 , all relations which connections tightness degree were less than 0.4475 were ignored. When the critical value was 0.875 , all relations which connections tightness degree were less than 0.875 were ignored. When the critical value was 1.3225 , all relations which connections tightness degree were less than 1.3225 were ignored. When the critical value was 1.77 , all relations which connections tightness degree were less than 1.77 were ignored. After calculating, the results were as shown in Table 1.

From Table 1, it could be seen that no matter which the critical value was, the overall density value of the network of outstanding students' MCS was greater than that of the network of medium students and general students' MCS. When the critical value was 0.4475 , the density value of the network of outstanding students' MCS was 2 times as big as that of medium students' MCS, the density value of the network of medium students' MCS was 1.5 times as big as that of general students' MCS. When the critical value was 1.3225 , the density value of the network of outstanding students' MCS was 30 times as big as that of medium students' MCS, the density value of the network of medium students' MCS was 2 times as big as that of general students' MCS. So the connections between above 44 concepts in the outstanding students' MCS should be more than that in the medium students' MCS and general students' MCS, especially the connections with higher tightness degree.

\section{The Cohesive Subgroups of MCS}

The cohesive subgroup of a network was a subset formed by some members of the network by connecting with each other directly. It was a maximal complete sub-graph and what it reflected was the uniformity and local grouping characteristics of the network (Liu, 2009; Luo, 2010). To understand the situation of cohesive subgroups in detail, we input three average value matrices into Ucniet6.0 and calculated three times respectively according to the critical value 1, 2, 3 by executing the command "Network $\rightarrow$ Regions $\rightarrow$ Components $\rightarrow$ Simple graphs". The reason why we chose these three numbers as critical values is the maximum value of all tightness degree was 3.35 , the minimum value of that was 0 . When the critical value was 1 , all relations which connections tightness degree were less than 1 were ignored. When the critical value was 2, all relations which connections tightness degree were less than 2 were ignored. When the critical value was 3, all relations which connections tightness degree were less than 3 were ignored. After calculating, the numbers of cohesive subgroups found and the numbers of subgroups whose number of concepts were more than 3 were as shown in Table 2. 
Table 3. The ego density of all concepts

\begin{tabular}{cccccccc}
\hline Concepts & $\begin{array}{c}\text { Outstanding } \\
\text { students }\end{array}$ & $\begin{array}{c}\text { Medium } \\
\text { students }\end{array}$ & $\begin{array}{c}\text { General } \\
\text { students }\end{array}$ & Concepts & $\begin{array}{c}\text { Outstanding } \\
\text { students }\end{array}$ & $\begin{array}{c}\text { Medium } \\
\text { students }\end{array}$ & $\begin{array}{c}\text { General } \\
\text { students }\end{array}$ \\
\hline Periodic transformation & 27.00 & 31.00 & 12.00 & Sinusoid & 28.00 & 15.00 & 17.00 \\
\hline Acute angle & 25.00 & 26.00 & 15.00 & Phase & 17.00 & 15.00 & 8.00 \\
\hline Trigonometric function value & 27.00 & 24.00 & 21.00 & Initial phase & 19.00 & 17.00 & 8.00 \\
\hline Trigonometric function line & 21.00 & 30.00 & 8.00 & Cosine & 17.00 & 16.00 & 9.00 \\
\hline Tangent line & 24.00 & 13.00 & 10.00 & Frequency & 15.00 & 17.00 & 8.00 \\
\hline Cosine line & 25.00 & 17.00 & 12.00 & Amplitude & 16.00 & 19.00 & 7.00 \\
\hline Sine line & 26.00 & 16.00 & 16.00 & Definition domain & 19.00 & 18.00 & 10.00 \\
\hline Directed line segment & 14.00 & 10.00 & 5.00 & Function domain & 19.00 & 20.00 & 10.00 \\
\hline Tangent function & 32.00 & 28.00 & 19.00 & Interval & 20.00 & 19.00 & 14.00 \\
\hline Cosine function & 31.00 & 27.00 & 18.00 & Decreasing function & 19.00 & 13.00 & 10.00 \\
\hline Sine function & 31.00 & 28.00 & 13.00 & Increasing function & 19.00 & 14.00 & 10.00 \\
\hline Central angle & 10.00 & 14.00 & 7.00 & Even function & 15.00 & 12.00 & 7.00 \\
\hline Radian & 14.00 & 15.00 & 6.00 & Odd function & 18.00 & 14.00 & 9.00 \\
\hline Angle system & 15.00 & 11.00 & 9.00 & Minimal positive period & 14.00 & 15.00 & 9.00 \\
\hline Trigonometric function & 38.00 & 43.00 & 28.00 & Period & 17.00 & 13.00 & 14.00 \\
\hline Round angle & 16.00 & 16.00 & 5.00 & Periodic function & 21.00 & 19.00 & 8.00 \\
\hline Quadrant angle & 18.00 & 13.00 & 10.00 & Functional images & 24.00 & 28.00 & 15.00 \\
\hline Terminal side & 16.00 & 17.00 & 7.00 & Inducted formula & 20.00 & 18.00 & 14.00 \\
\hline Initial line & 16.00 & 13.00 & 6.00 & Tangent function value & 24.00 & 22.00 & 10.00 \\
\hline Zero angle & 15.00 & 13.00 & 6.00 & Cosine function value & 21.00 & 21.00 & 15.00 \\
\hline Radian system & 20.00 & 15.00 & 8.00 & Obtuse angle & 28.00 & 15.00 & 5.00 \\
\hline Arbitrary angles & 16.00 & 15.00 & 14.00 & Unit circle & 17.00 & 15.00 & 16.00 \\
\hline & & & & & &
\end{tabular}

It could be seen from Table 2, the numbers of cohesive subgroups in MCS of outstanding students were always less than or equal to the numbers of cohesive subgroups in MCS of other two kind students. The cohesive subgroups whose number of concepts was more than 3 always existed in MCS of outstanding students, while in MCS of medium and general students it did not. The MCS of outstanding students always could be divided into several bigger subgroups and some small subgroups. While the MCS of medium and general students did not. When the critical value was 1, a cohesive subgroup whose number of concepts was 32 appeared in in MCS of outstanding students, it contained $72.7 \%$ of all concepts. The largest cohesive subgroups in MCS of medium students only contained 6 concepts, no cohesive subgroup whose number of concepts was more than 3 existed in MCS of general students. It seemed that most concepts in MCS of outstanding students were connected each other directly. While in MCS of other students, the concepts connected each other directly not much.

\section{The Ego Density of Members in MCS}

The ego density of members in a network referred to the number of relations that formed by this member connecting others of the network. What it revealed was who was the accumulation point in the network (Liu, 2009; Luo, 2010). We input three average value matrices into Unciet6.0 and calculated the ego density of members in MCS of three different level students by executing the command "Network $\rightarrow$ Ego-networks $\rightarrow$ Egonet basic measures". After calculating, all values obtained of ego density were as shown in Table 3.

From Table 3, it could be seen that the values of ego density of concepts in MCS of outstanding students were generally bigger than that of concepts in MCS of medium students, and that of concepts in MCS of medium students was bigger than that of concepts in MCS of general students. Indeed the average value of the values of ego density of concepts in MCS of outstanding students was 20.545, while the average values of values of ego density of concepts in MCS of medium and general students were respectively 18.409 and 11.091. There was a significant difference between the values of ego density of concepts in MCS of outstanding and medium students and that of ego density of concepts in MCS of general students $(t=8.227, p=0.000 ; t=5.931 p=0.000)$. This should indicate the connections of concepts in MCS of outstanding students were more extensive than that in MCS of other students again.

Additionally, it could be found that the concept which had the biggest value of ego density in MCS of all students was always Trigonometric function. Just the biggest values of ego density in MCS of three level students were different, they were respectively 38,43 and 28 . That meant the concept of Trigonometric function was the prominent accumulation point in MCS, it should be in the central place of whole MCS. Considering the Trigonometric function was abstract and of the highest generalization level concept among 44 concepts above, it 
Table 4. The ego centrality of all concepts

\begin{tabular}{|c|c|c|c|c|c|c|c|}
\hline Concepts & $\begin{array}{c}\text { Outstanding } \\
\text { students }\end{array}$ & $\begin{array}{l}\text { Medium } \\
\text { students }\end{array}$ & $\begin{array}{c}\text { General } \\
\text { students }\end{array}$ & Concepts & $\begin{array}{c}\text { Outstanding } \\
\text { students }\end{array}$ & $\begin{array}{l}\text { Medium } \\
\text { students }\end{array}$ & $\begin{array}{c}\text { General } \\
\text { students }\end{array}$ \\
\hline Periodic transformation & 19.3 & 10.556 & 6.5 & Sinusoid & 12.85 & 4.037 & 5.357 \\
\hline Acute angle & 13.65 & 5.63 & 4.143 & Phase & 9.85 & 4.259 & 3.071 \\
\hline Trigonometric function value & 13.55 & 8.741 & 5.5 & Initial phase & 9.4 & 4.778 & 2.571 \\
\hline Trigonometric function line & 19.25 & 10.296 & 2.786 & Cosine & 7.95 & 4.926 & 1.929 \\
\hline Tangent line & 17 & 5 & 3.929 & Frequency & 8.75 & 5.333 & 2.929 \\
\hline Cosine line & 18.95 & 6.852 & 4.286 & Amplitude & 9.2 & 6.222 & 2.357 \\
\hline Sine line & 16.4 & 5.222 & 4.929 & Definition domain & 16.35 & 7.852 & 3.286 \\
\hline Directed line segment & 7.6 & 2.667 & 2.429 & Function domain & 15.8 & 7.889 & 3.929 \\
\hline Tangent function & 39.8 & 12.074 & 7.643 & Interval & 17.2 & 7.963 & 4.071 \\
\hline Cosine function & 38.3 & 14.333 & 7.571 & Decreasing function & 9.7 & 7.222 & 2.929 \\
\hline Sine function & 35.45 & 13.148 & 5.929 & Increasing function & 10.7 & 7.963 & 3.214 \\
\hline Central angle & 6.3 & 4.296 & 2.071 & Even function & 8.25 & 4.741 & 2.929 \\
\hline Radian & 7.95 & 5.667 & 2 & Odd function & 9.4 & 4.815 & 3.429 \\
\hline Angle system & 10 & 5.259 & 2.429 & Minimal positive period & 15.9 & 4.111 & 4.571 \\
\hline Trigonometric function & 27.8 & 14.259 & 8.5 & Period & 16.55 & 6.259 & 5.857 \\
\hline Round angle & 6.2 & 3.556 & 1.5 & Periodic function & 17.1 & 7.519 & 4.5 \\
\hline Quadrant angle & 10.8 & 4.667 & 4.143 & Functional images & 16.4 & 13.185 & 4.357 \\
\hline Terminal side & 8.9 & 5.111 & 3.071 & Inducted formula & 10.05 & 5.481 & 4.786 \\
\hline Initial line & 9.1 & 4.037 & 2.786 & Tangent function value & 9.95 & 5.148 & 3.286 \\
\hline Zero angle & 7.9 & 2.852 & 1.714 & Cosine function value & 9.15 & 4.667 & 4.286 \\
\hline Radian system & 12.35 & 5.222 & 3.857 & Obtuse angle & 7.45 & 3.259 & 1.786 \\
\hline Arbitrary angles & 15.15 & 6.296 & 6.143 & Unit circle & 10.75 & 6.333 & 6.571 \\
\hline
\end{tabular}

seemed that the abstract concept with the highest generalization level was the most important in MCS, it connected with other concepts extensively.

It was noteworthy there were additional three concepts whose values of ego density were close to the value of Trigonometric function in MCS of outstanding students, they were Tangent function, Cosine function, Sine function, their values of ego density differed from others' values significantly $(t=-12.878, p=0.000 ; t=-11.754, p=0.000$; $t=-11.754, p=0.000)$. While there were additional two concepts whose values of ego density were close to the value of the Trigonometric function in MCS of medium students, they were Periodic transformation and Trigonometric function line. Their values of ego density differed from others' value significantly $(t=-12.636, p=0.000 ; t=-11.632$, $p=0.000$ ). There were no similar concepts in MCS of general students. So it seemed that there were some additional remarkable accumulation points in MCS of outstanding students beside the prominent accumulation point.

\section{The Ego Centrality of MCS}

The ego centrality of a member in a network referred to the numbers of relations that formed by this member connecting with others directly. It was different from the ego density of a member, what it revealed was the influence power or force of this member in the network (Liu, 2009; Luo, 2010). Inputting three average value matrices into Unciet 6.0, we calculated the ego centrality of the concepts in MCS of three different level students by executing the command "Network $\rightarrow$ Centrality $\rightarrow$ degree". After that, all values obtained of ego centrality of 44 concepts were as shown in Table 4.

From the Table 4, it could be seen that the values of ego centrality of concepts in MCS of outstanding students were generally greater than that in MCS of medium students and general students. Indeed, the average value of values of ego centrality of concepts in MCS of outstanding students was 14.1. The average value of values of ego centrality of concepts in MCS of medium students was 6.5842. The average value of values of ego centrality of concepts in MCS of general students was 3.9968. There was the significant difference between the values of ego centrality of concepts in MCS of outstanding students and that of ego centrality of concepts in MCS of medium and general students significantly $(t=5.895, p=0.000 ; t=8.296, p=0.000)$. So, the concept in MCS of outstanding students should have more direct connections with other concepts.

It could be found that the concept of the biggest value of ego centrality in MCS of outstanding students was the Tangent function, and its value of ego centrality was 39.8. The concept with the biggest value of ego centrality in MCS of medium level students was Cosine function, and its value of ego centrality was 14.33 . The concept with the biggest value of ego centrality in MCS of general students was the Trigonometric function, and its value of ego centrality was 8.5. Hence, the concepts who had the most direct connections with other concepts in MCS of outstanding and medium students were different. 
Comparing these three concepts with others, it could be seen, the concept of Tangent function and the concept of Cosine function were relatively concrete concepts and used frequently in student's mathematics learning, especially in students' mathematics problem solving, and their generalization level was not high. While the concept of Trigonometric function was abstract and of the highest generalization level and used seldom in students' mathematics problem-solving. So it seemed that the concrete concepts whose generalization level was not high and used frequently were the most influential in MCS of outstanding students, namely they had more direct connections with other concepts.

Additionally, the concept of the Cosine function and Sine Function in MCS of outstanding students had the higher value of ego centrality too, and the two values were close to the value of ego centrality of Tangent function in MCS of outstanding students. Their values of ego centrality differed from others' value significantly $(t=-20.331$, $p=0.000 ; t=-17.936, p=0.000)$. The concept of Trigonometric function, Sine Function, Functional image and Tangent function had higher values of ego centrality in MCS of medium students, the four values were close to the value of ego centrality of Cosine function in MCS of medium students. Their values of ego centrality differed from others' value significantly $(t=-16.804, p=0.000 ; t=-14.372, p=0.000 ; t=-14.453, p=0.000 ; t=-12.02, p=0.000)$. The concept of the Cosine function and Tangent function in MCS of general students had the higher value of ego centrality too, the two values were close to the value of ego centrality of Tangent function in MCS of general students. Their values of ego centrality differed from others' value significantly $(t=-13.875, p=0.000 ; t=-14.154, p=0.000)$. So it seemed there were a number of influential concepts in MCS of outstanding students, they all were concrete and used frequently and of slightly lower generalization level.

\section{DISCUSSIONS}

The MCS played a vital role in individual mathematical activities, almost all teachers expected to help their students form a GMCS (Skemp, 1971; Ausubel, 1994; Zhang, 2003; Dixon, 2005; Wilkerson-Jerde \& Wilensky, 2011; Sofia et al., 2017). To achieve this goal, much research with various method had been conducted. Reviewing these research, it could be seen there some aspects about GMCS were still not be explored in depth (Sun and Yang, 2015). Therefore, this research chose the concepts about trigonometric function as materials, adopted the network data analysis method, analyzed the overall density, subgroups, ego density, and ego centrality of MCS of outstanding students.

From the data analyzing above, it could be seen that the overall density of MCS of outstanding students was greater than that of MCS of medium and general students, especially when only the bigger value of tightness degree of connections was considered, this situation became more clear. So the connections between above 44 concepts in the outstanding students' MCS should be more than that in the medium level students' MCS and general students' MCS, especially those connections with higher tightness degree. Because the overall density was a ratio of numbers of actual relations to numbers of theoretical relations between members in the network, what it reflected was the relative quantity of relations in a network.

This situation could be found from another aspect too, that was ego density. From the analyzing above, it could be found that the values of ego density of concepts in MCS of outstanding students were generally and significantly greater than that of concepts in MCS of medium and general students. While the ego density of a member was the number of relations that formed by this member connecting with others of the network. So the connections formed by each concept with others in MCS of outstanding students should be more than the connections formed by each concept with others in MCS of medium and general students. Hence, overall, the connections in MCS of outstanding students must be more than that in MCS of medium and general students. This result obviously supported some former views (Wang and Wang, 2004; Ifenthaler, 2011). However, they were still a little different, because the former research did not explain the situation of connections with higher tightness degree.

The connections could be classified into two types, namely direct and indirect connections. What type do the connections in MCS of outstanding students belong to? From the analyzing above, it could be seen the numbers of cohesive subgroups were less and the cohesive subgroups whose number of concepts was more than 3 always existed in MCS of outstanding students. When the critical value was 1, a cohesive subgroup whose number of concepts was 32 appeared in MCS of outstanding students, it contained $72.7 \%$ of all concepts. While the cohesive subgroup of a network was formed by some members of the network by connecting each other directly and tightly. So most concepts in MCS of outstanding students should be connected each other directly, or most connections in MCS of outstanding students should be direct.

This situation should be found from the ego centrality. From the analyzing above, it could be found that the values of ego centrality of concepts in MCS of outstanding students were generally greater than that in MCS of medium students and general students. While the ego centrality was the number of relations formed by this member connecting with others directly. This result obviously was different from the views of "standard pyramid" about MCS (Wang and Zheng, 2008). 
Additionally, from the analyzing about ego density of concepts, it could also be found that the concept of Trigonometric function had the biggest value of ego density in MCS of all students. So it should be the concept with the most connections and was the prominent accumulation point in all MCS. Besides, it could be found there are 3 and 2 other concepts having the higher value of ego density respectively in MCS of outstanding students and in MCS of medium students, however, there was no similar concept in MCS of general students. So the MCS of outstanding students should have more abstract concepts as accumulation points to connect with other concepts.

Even the concept of Trigonometric function was the prominent accumulation point in MCS of outstanding students, it was not the most influential. Because it could be found from the analyzing about ego centrality of concepts, that the concept of the biggest value of ego centrality in MCS of outstanding students was the Tangent function. Besides, since the concept of the Cosine function and Sine function had the bigger value of ego centrality which was close to that of the Tangent function. So there were a number of influential concepts in MCS of outstanding students. Meanwhile, considering the Tangent function, the Cosine function and Sine function all were concrete and used frequently concepts, it could be seen there were a number of concrete and frequently used concepts in MCS of outstanding students connecting with other concepts directly.

The outstanding students generally were deemed to hold GMCS (Tsai, 2001, Wang and Wang, 2004). Thus, the GMCS should have following characteristics: (1) The connections between the concepts in GMCS were more extensive, especially those connections with higher tightness degree. (2) Most connections in GMCS were direct. (3) There were more abstract concepts as accumulation points connecting with other concepts. (4) There were a number of concrete and frequently used concepts connecting with other concepts directly.

Thus, the mathematics teachers should help students to construct extensive connections between mathematics knowledge in their mind in the process of teaching, especially the direct connections, so as to make students form a compact and smart MCS. Meanwhile, mathematics teachers should pay attention to all abstract mathematics knowledge with higher generalization level and instruct students construct extensive connections between this kind of mathematics knowledge and others so as to form more mathematics knowledge accumulation points in their MCS. Moreover, mathematics teachers should attach importance to the frequently and widely used mathematics knowledge and help students to construct the direct connections between this kind of mathematics knowledge and others.

These new findings enriched the existed research results, expanded the research field about MCS, pointed out the direction and target for educators helping their students form GMCS. Moreover, this research demonstrated the network data analysis method was feasible and effective when it was applied in research about MCS, it could undoubtedly be used in related researches. So this research promoted researches about MCS, especially those researches about the organization of knowledge in cognitive structure.

However, this research had one limitation at least objectively, that was the participants we chose was just students in Shandong province, China, and the number of participants was only 31. A small number of participants coming from the same district would definitely affect the accuracy of the results. So we will choose more appropriate participants from different districts to do more deep and extensive research. And then we will compare and analyze all results and give a more accurate conclusion about organizational characteristics of mathematics knowledge in GMCS.

\section{FUNDING}

This research was supported by the Shandong provincial education department grant number SDYY17127 and the Shandong normal university grant number 2016JG29.

\section{REFERENCES}

Alison P., Markus, G., \& Alan, S. (2013). Developments in Research on Mathematical Practice and Cognition. Topics in Cognitive Science, 5(2), 224-230.

Anderson O. R., \& Demetrius O. J. (1993). A Flow-Map Method of Representing Cognitive Structure Based on Respondents' Narrative Using Science Content. Journal of Research in Science Teaching, 30(8), 953-969.

Ausubel D. P. (1963). The Psychology of Meaningful Verbal Learning. New York: Grune and Stratton.

Ausubel D. P. (1994). Educational Psychology: a Cognitive View. Beijing: The people education Press.

Bruner J. S. (1974). Beyond the Information Given. London: Allen and Unwin.

Bruner J. S. (1989). A Selection of Bruner's Education Works. Translated by Shao, R. Zh. Beijing: People's Education Press.

Cao, C. H., \& Cai J. F. (1989). Introduction to Mathematics Education. Nanjing: Jiangsu Education Publishing House. 
Casas, L., Luengo, R., \& Godinho, V. (2011). Software GOLUCA: Knowledge Representation in Mental Calculation. US-China Education Review, 4, 592-600.

Chen, J. (2003). The Study of Optimizing and Perfecting Mathematics Cognition Structures of Middle School Class Teaching (Master Thesis). Jinan: Shandong Normal University.

Dixon, J. A. (2005). Mathematical Problem Solving: the Roles of Exemplar, Schema, and Relational Representations. In J. I. D. Campbell (Ed.), Handbook of Mathematical Cognition. NewYork: Psychology Press.

Enger, S. K. (1996). Concept Mapping: Visualizing Students Understanding. Paper Presentado en el Anual Meeting of Mid-South American Educational Research Association, Tuscalossa (ERIC Document Reproduction Service No ED 406413).

Fenker, R. M. (1975). The Organization of Conceptual Materials: A Methodology for Measuring Ideal and Actual Cognitive Structures. Instructional Science, 4, 33-57.

Geeslin, W. E., \& Shavelson, R.J. (1975). Comparison of Content Structure and Cognitive Structure in High School Students' Learning of Probability. Journal of Research in Mathematics Education, 12, 109-120.

Guan, P. (1998). Principles of Cognitive Psychology on Forming Good Mathematical Cognitive Structure. Theory and Practice of Education, 18(2), 40-45.

Han, B, \& Wang, G. M. (2005). Role of Cognitive Structure and Reflections on It in the Process of Problem Solving. Journal of Middle School Mathematics, (6), 5-7.

He, X. Y. (2002). Instructional Strategies on Constructing well Mathematical Cognitive Structure. Journal of Mathematics Education, 11(1), 24-27.

Hou, K., Zou, H., Liu, Y., Jin, C. C., \& Jiang, S. (2014). Peer Group Influence on Adolescents' Problem Behavior: a Social Network Analysis. Psychological Development and Education, (03), 259-267.

Ifenthaler, D. (2011). Identifying Cross-domain Distinguishing Features of Cognitive Structure. Education Technology Research Development, 59, 817-840.

Ifenthaler, D., Masduki, I., \& Steel, N. M. (2001). The Mystery of Cognitive Structure and How We Can Detect It: Tracking the Development of Cognitive Structures over Time. Instructor Science, (39), 41-61.

Jin, Q. F. (2002). Research on Mathematics Cognitive Structure of Students in Elementary School and Teaching Management in Classroom (Master Thesis). Changchun: Northeast Normal University.

Jin, X. F. (2011). Talk about the Establishment of Good Mathematical Cognitive Structure again. New Curriculum Research, 209, 179-181.

Johnson, D. T. (2000). Teaching Mathematics to Gifted Students in a Mixed-Ability Classroom. (Eric DIGESTE594).

Jonassen, D., Beissner, K., \& Yacci, M. (1993). Structural Knowledge: Techniques for Representing, Conveying and Acquiring Structural Knowledge. Hillsdale, NJ: Laurence Erlbaum Associates.

Kong, F. Z., \& Zeng, Z. (2009). Psychology of Mathematics Learning. Beijing: Peking University press.

Lavigne, N. C. (2005). Mutually Informative Measures of Knowledge: Concept maps Plus Problem Sorts in Statistics. Educational Assessment, 10(1), 39-71.

Li, M. Z. (1998). A Study on Mathematics Problem Solving Strategies and Its Training. Journal of Guizhou Normal University (Natural Science), 2, 72-76.

Li, Sh. Q. (2001). PME: Psychology of Mathematics Education. Shanghai: East China Normal University Press.

Lindstrom, C., \& Sharma, M. D. (2011). Teaching Physics Novices at University: A Case For Stronger Scaffolding. Physical Review Special Topics-Physics Education Research, 7(1), 010109.

Liu, J. (2009). Lecture Notes on Whole Network Analysis. Shanghai: Truth \& Wisdom Press.

Liu, X. (1994). The Validity and Reliability of Concept Mapping as an Alternative Science Assessment When Item Response Theory is Used for Scoring. Paper Presented at the Annual Meeting of the American Educational Research Association, New Orleans (ED 370992).

Lu, J., \& Yu, P. (2010). Reflection of Research about the Chinese Mathematics Cognitive Structure. Journal of Mathematics Education, 19(2), 19-22.

Luo, J. D. (2010). Lecture notes on Social Network Analysis. Beijing: Social Sciences Academic Press.

Ma, Sh. Q., Jiao, C., \& Zhang, M. Q. (2011). Application of Social Network Analysis in Psychology. Advances in Psychological Science, (05), 755-764.

Maker, C. J. (1981). Curriculum Development for the Gifted (Hakluyt Society third series). Aspen Publications.

Mi,M., \& Hou, W. S. (2011). Cognitive Structure Affect Solving Mathematics Problem. Journal of Yan'an Vocational E Technical Institute, 1, 68-69. 
Ministry of Education of the people's Republic of China. (2003). The Standards for Senior High School Mathematics Curriculum. Beijing: People's Education Press.

Ministry of Education of the people's Republic of China. (2012). The Standards for Compulsory education Mathematics Curriculum. Beijing: Beijing Normal University Press.

Muller, D. A., Sharma, M. D., \& Reimann, P. (2008). Raising Cognitive Load with Linear Multimédia to Promote Conceptual Change. Science Education, 92(2), 278-296.

National Council of Teachers of Mathematics. (2000). Principles and Standard for School Mathematics. Reston: Author.

Novak, J. D. (1998). Learning, Creating, and Using Knowledge: Concept Maps as Facilitative Tools in School and Corporations Mahwah. New Jersey: Lawrence Erlbaum Assoc.

Papert, S. (1993). The Children's Machine: Rethinking School in the Age of the Computer. New York: Basic Books.

Preece, P. F. W. W. (1976). Mapping Cognitive Structure: A Comparison of Models. Journal of Educational Psychology, 68 (1), 1-8.

Ruiz-Primo, M. A., \& Shavelson, R. J. (1997). Concept-map Based Assessment: On Possible Sources of Sampling Variability. U.S. Department of Education, Office of Educational Research and Improvement, Educational Resources Information Center.

Ruiz-Primo, M. A., Schultz, S. E., Li, M., \& Shavelson, R. J. (2001). Comparison of the Reliability and Validity of Scores from Two Concept-mapping Techniques. Journal of Research in Science Teaching, 38(2), 260-278.

Shavelson, R. J., Ruiz-Primo, M. A., \& Wiley, E. W. (2005). Windows into the Mind. Higher Education: The International Journal of Higher Education and Educational Planning, 49(4), 413-430.

Skemp, R. (1971). The Psychology of Learning Mathematics. London: Penguin Books.

Sofia, M. V. C., Vitor, G. L., Luis, M. C. G., \& Ricardo, L. G. (2017). Evaluation of Changes in Cognitive Structures after the Learning Process in Mathematics. International Journal of Innovation in Science and Mathematics Education, 25(2), 17-33

Sun, D. D., \& Yang, Z. Zh. (2015). Research on Good Mathematical Cognitive Structure in Mainland China. Advances in Social and Behavioral Sciences: Proceeding of 2015 3rd Asian Conference on the Social Sciences, 15, 216-219.

Sun, D. D., \& Yang, Z. Zh. (2015). Study on Content and Organization of Mathematical Cognitive Structure in Mainland China. Advances in Intelligent Systems Research, 283.

Tsai, C. C. (2001). Probing Students' Cognitive Structures in Science: The Use of a Flow Map Method Coupled with a Meta-Listening Technique. Studies in Educational Evaluation, (27), 257-268.

Tu, R. B. (2003). The cognition of Mathematical Teaching. Nanjing: Nanjing Normal University.

Wainer, H., \& Kaye, K. (1974). Multidimensional Scaling of Concept Learning in an Introductory Course. Journal of Educational Psychology, 66, 591-598.

Wang, G. M., \& Wang, Y. (2004). The Comparison of Top and Ordinary Students' Mathematical Cognitive Structures in Senior High School, the Possible Reasons for difference, and Teaching Suggestions. Reference for Middle School Mathematical Education, (12), 1-4

Wang, W. J., \& Zheng, Y. P. (2008). The Characteristic of Good Mathematical Cognitive Structure and it's Instructional Enlightment. Friend of Science Amateurs, 23, 113-114.

Wang, Y. W. (2013). On Cultivating Students' Good Cognitive Structure in Advanced Mathematics Teaching. Journal of Chendu Normal University, 29(11), 119-121.

Wilkerson-Jerde, M., \& Wilensky, U. (2011). How do Mathematicians Learn Math?: Resources and Acts for Constructing and Understanding Mathematics. Educational Studies in Mathematics, 78, 21-43

Wo, J. Zh. (2000). Cognitive Structure and Information Processing. Journal of Beijing Normal University, (1), 80-86

Wu, X. F., \& Guo X. H. (1997). Mathematics Education. Wuhan: Huazhong Normal University Press.

Xu, W., Chen, G. H, Zeng, Y., \& Zhang, W. X. (2011). A New Approach of Relation Research: Social Network Analysis. Journal of Psychological Science, 34(2), 499 -504.

Yan, Z. X., \& Huang, D. C. (2005). How to Construct the Students' Good Mathematical Cognitive Structure. Journal of Shenyang Agricultural University (Social Science Edition), 2, 190-191.

Yang, Q. (1993). On the Influence of Cognitive Structure on Mathematics Learning - One of the Explores about Psychological Factors that Have Influence on Mathematics Learning. Journal of Mathematics Education, (1), 66-70.

Yu, P. (2004). Influence of Self-controlling Ability and CPFS Structure on the Mathematical Achievement in High School Students. Journal of Mathematics Education, 13(1), 23-26. 
Yu, P. (2004). Psychology of Mathematics Education, Nanning: Guangxi Education Publishing House.

Yu, P., Lian, S. Q., \& Wo, X. H. (2011). Review on Research about Psychology of Mathematics Education for 30 Years in Mainland China. Beijing: Science Press.

Zhang, Ch. W. (2003). The Psychological Meaning of Students' Mathematical Cognitive Structure in Mathematics Teaching. Research of Mathematics Teaching-Learning, (12), 2-4.

Zhang, J. W., \& Chen, Q. (2000). Test Method of Cognitive Structure. Journal of Psychological Science, (06), 750-751.

Zhang, M. L. (2007). How the Knowledge and Cognitive Structure Promote Each Other? China Education Daily, (5), 11-23.

Zhang, Y., \& Wu, J. H. (2012). The Function of Good Mathematical Cognitive Structure. Proceedings of Conference on Psychology and Social Harmony.

Zhao, C. X. (2013). Optimize and Improve the Mathematics Cognitive Structure of Students in the Inquiry Learning. Educational Practice and Research, 5, 53-55.

\section{http://www.ejmste.com}

